\title{
Distribution of HPV genotypes in cervical intraepithelial lesions and cervical cancer in Tanzanian women
}

\author{
Adriana C Vidal', Susan K Murphy², Brenda Y Hernandez ${ }^{3}$, Brandi Vasquez ${ }^{4}$, John A Bartlett ${ }^{5}$, Olola Oneko ${ }^{6}$, \\ Pendo Mlay ${ }^{6}$, Joseph Obure ${ }^{6}$, Francine Overcash ${ }^{1}$, Jennifer S Smith ${ }^{7}$, Mike van der Kolk ${ }^{8}$ and Cathrine Hoyo ${ }^{1 *}$
}

\begin{abstract}
Background: Infection with human papillomavirus (HPV) is associated with uterine cervical intraepithelial neoplasia (CIN) and invasive cancers (ICC). Approximately $80 \%$ of ICC cases are diagnosed in under-developed countries. Vaccine development relies on knowledge of HPV genotypes characteristic of LSIL, HSIL and cancer; however, these genotypes remain poorly characterized in many African countries. To contribute to the characterization of HPV genotypes in Northeastern Tanzania, we recruited 215 women from the Reproductive Health Clinic at Kilimanjaro Christian Medical Centre. Cervical scrapes and biopsies were obtained for cytology and HPV DNA detection.

Results: 79 out of 215 (36.7\%) enrolled participants tested positive for HPV DNA, with a large proportion being multiple infections (74\%). The prevalence of HPV infection increased with lesion grade (14\% in controls, $67 \%$ in CIN1 cases and 88\% in CIN2-3). Among ICC cases, 89\% had detectable HPV. Overall, 31 HPV genotypes were detected; the three most common HPV genotypes among ICC were HPV16, 35 and 45. In addition to these genotypes, co-infection with HPV18, 31, 33, 52, 58, 68 and 82 was found in 91\% of ICC. Among women with CIN23, HPV53, 58 and 84/83 were the most common. HPV35, 45, 53/58/59 were the most common among CIN1 cases.

Conclusions: In women with no evidence of cytological abnormalities, the most prevalent genotypes were HPV58 with HPV16, 35, 52, 66 and 73 occurring equally. Although numerical constraints limit inference, findings that 91\% of ICC harbor only a small number of HPV genotypes suggests that prevention efforts including vaccine development or adjuvant screening should focus on these genotypes.
\end{abstract}

Keywords: Human papillomavirus (HPV), cervical intraepithelial neoplasia (CIN), invasive cervical cancer (ICC)

\section{Background}

Globally, cervical cancer remains the third most common cancer, representing $8.8 \%$ of all cancers in women [1]. Infection with human papillomavirus (HPV) is associated with low-grade (LSIL) and high-grade (HSIL) intraepithelial precursor lesions of the uterine cervix as well as invasive cervical cancer (ICC) [2]. More than 200 HPV genotypes, subtypes and variants have been reported [3], of which approximately 14 genotypes are classified as oncogenic [4,5]. HR-HPV DNA is detected in almost all ICC cases [6].

\footnotetext{
* Correspondence: cathrine.hoyo@duke.edu

'Department of Community and Family Medicine, and Program of Cancer Detection, Prevention and Control, Duke University School of Medicine,

Durham, NC, USA

Full list of author information is available at the end of the article
}

In developed and in many less-developed countries, assessing the effectiveness of prophylactic vaccines against HR-HPV16 and 18, and further vaccine development will depend on knowledge of the distribution of these HPV genotypes in different regions [7-10]. HPV types 16 and 18 are consistently the two most common types in invasive cancer, globally. One study suggested that vaccination against HPV16 and 18 could prevent almost 70-80\% of ICC worldwide-[11]. It has been suggested that vaccine efficacy could be increased to $95 \%$ for CIN2-3 and 92\% for cancer by including an additional $12 \mathrm{HPV}$ genotypes detected in an Icelandic women population [7]. However, data collected from different countries have shown fluctuations in the

\section{Biomed Central}

(c) 2011 Vidal et al; licensee BioMed Central Ltd. This is an Open Access article distributed under the terms of the Creative Commons Attribution License (http://creativecommons.org/licenses/by/2.0), which permits unrestricted use, distribution, and reproduction in any medium, provided the original work is properly cited. 
distribution of the third and even less common oncogenic HPV types between regions $[9,12]$.

Given the suboptimal sensitivity and specificity of cytology-based screening, and the low screening coverage in most African countries, immunization against the most prevalent HR-HPV genotypes affecting each region may represent the most effective means to long-term ICC prevention [13]. To date, few studies describing single and multiple HPV infections according to CIN grades have been conducted in African populations where a wide range of HPV genotypes prevail [14-16]. Moreover, many of these studies have not described HPV infection in ICC cases $[17,18]$. Herein we report on the distribution of HPV genotypes in Northeastern Tanzania, with the aim of identifying the most frequent HPV genotypes associated with different CIN grades and ICC in this population.

\section{Methods}

\section{Study participants}

Procedures for this study were approved by Research Ethics Boards at KCMC and Duke University. Between November 2008 and March 2009, eligible study participants were identified from the appointment books of the Reproductive Health Clinic (RHC) at Kilimanjaro Christian Medical Centre (KCMC), a Cervical Cancer prevention clinic funded by the World Health Organization (http://www.afro.who.int/en/tanzania/who-country-officetanzania.html). KCMC is a tertiary care facility that serves a catchment area of $\sim 10$ million individuals. Eligible participants were 18 years or older and had no history of an abnormal Pap test. ICC patients comprised new cases to the $\mathrm{KCMC}$ who were also 18 years or older and were referred for colposcopic directed evaluations. A trained nurse interviewer enrolled a total of 249 women; all but 2 approached agreed to participate (99\% response rate). Of these, 12 patients were excluded due to missing or inadequate Pap smear, refusal of serostatus HIV-1 antibody test, and diagnosis of an unrelated co-morbid condition. The final dataset of participants, $n=215$ (86\%), were those with questionnaire, CIN status, and HPV genotype data.

\section{Data collection}

\section{Questionnaires}

A trained nurse-interviewer obtained informed consent from all participants, and administered a standardized 40-minute questionnaire, in person. The questionnaire collected information on socio-demographic characteristics (e.g., age, marital status), type of marriage (polygamy vs. monogamy), tribe, educational attainment, cigarette smoking, alcohol intake, reproductive history (e.g., menarche, parity and gravidity), sexual history (e.g., lifetime number of sexual partners, age at first intercourse), and medication and supplement use.

\section{Specimens}

Two cervical scrapes were obtained from each participant using Ayres spatula and Cytobrush. One specimen was smeared on a glass slide for cytological evaluation for patient care. A second specimen was collected using a Cytobrush and rinsed into Preserv- Cyt ${ }^{\mathrm{TM}}$ media (Hologic, Inc, Malborough, MA). Following specimen collection, routine cervical screening by Visual Inspection with Acetic acid (VIA) was performed. Biopsies of lesions were obtained during colposcopy when indicated. Patients with positive findings by VIA or direct examination were triaged and treated accordingly. The remaining patients were given return appointments to follow up on results within two weeks, and were treated accordingly.

\section{Ascertainment of CIN and Carcinoma}

Papanicolaou smears and biopsy specimens were processed and read by the staff pathologist at KCMC- using standard conventions according to ASCCP guidelines as appropriate (http://www.asccp.org/). Once a month, medical charts were reviewed by BV for HIV-1 test and cyto-pathological results, to classify cases using the Bethesda classification system [19]. Based on pathology and medical records findings, results were then coded as "no evidence of cytological abnormality", "mild dysplasia" including LSIL and CIN1, "moderate dysplasia" including HSIL and CIN2-3, or "cancer" which included squamous cell carcinoma and two adeno-squamous carcinomas of the uterine cervix. None of the specimens were read as "atypical cells of uncertain significance (ASCUS)". These results were available as part of their clinic records, and pathologists entered them into the database. These clinical results were then compiled and transferred securely to Duke University.

\section{HPV genotyping}

ThinPrep ${ }^{\circledR}$ specimens and homogenized aliquoted biopsies collected during the same visit were shipped to the University of Hawaii Cancer Center. Following DNA extraction, PGMY09/PGMY11 primers [20] were used in PCR to target a 450-bp region of the HPV L1 genome. Amplification of the human $\beta$-globin gene was included as an internal control for sample sufficiency. All specimens were suitable for viral DNA analysis. HPV-positive specimens were subsequently genotyped by using the HPV Linear Array ${ }^{\circledR}$ (Roche Molecular Systems Inc., Branchburg, NJ, USA).

\section{Ascertainment of HIV-1 infection status}

Peripheral blood samples were centrifuged to separate the plasma and buffy coat. Plasma samples were used to test for HIV-1 infection using two rapid HIV tests (Capillus HIV-1/HIV-2, Trinity Biotech PLC, Bray, Country Wicklow, Ireland, and Determine HIV-1/2, Abbott Laboratories, Abbott Park, IL). Reactive specimens were then tested using Western blot as is standard 
clinical practice (Genetic Systems HIV-1 Western blot kit; Bio-Rad, Hercules, CA) [21].

\section{Statistical analyses}

For each disease endpoint (CIN1, CIN2-3, ICC and women with no evidence of cervical abnormalities), we computed the proportion of single and multiple HPV infections, and grouped them according to potential oncogenicity using WHO-recommended categories [22]. Group 1 comprises high-risk (HR) or the most potent type HPV16, followed by HPV18, 31, 33, 35, 39, 45, 51, $52,56,58$, and 59; group 2A includes HPV68; group 2B includes HPV26, 53, 66, 67, 70, 73, and 82 with limited evidence for human cervical cancer; and group 3 includes low-risk (LR) HPV types 6 and 11 [22]. We estimated the average number of HPV infections per woman by dividing the total number of HPV genotypes in multiple infections by the number of women infected. To estimate the attribution of each HPV genotype to CIN or ICC beyond the known HR-HPV, we estimated proportions in each case group with and without HRHPV genotypes. Statistical analyses were conducted using SAS 9.2 (SAS Institute, Cary, NC).

\section{Results}

Cervical cytology and HPV testing was conducted among 215 Northern Tanzanian women, 55\% were Chaga, $15 \%$ were Pare and $30 \%$ were from other tribes. Although the median age of all cases was 45 years, women with no evidence of cervical abnormalities or controls (mean age 40.3 years, $s d=9.87$ ), and CIN1 cases (mean age 35.7 years $s d=12.2$ ) were younger than women with CIN2-3 and ICC whose mean ages were 44.7 years, $(\mathrm{sd}=9.82)$ and 55.2 years, $(\mathrm{sd}=12.3)$, respectively. Controls and case groups did not vary significantly by tribe, cigarette smoking and lifetime number of sexual partners, although controls were less likely to be infected with any HPV. HIV-1 infection was more frequently reported by CIN than ICC cases or controls while OC use was more frequently reported by CIN cases and controls than ICC cases (Table 1).

Table 2 shows the total number of HPV-infected individuals and the distribution of HPV genotypes by cervical intraepithelial lesion or cervical cancer status. Of 215 participants, 79 (36.7\%) were HPV-positive and of these, $20(25 \%)$ had no evidence of cytological abnormality, 12 (15\%) had CIN1, 14 (17\%) had CIN2-3, and 33 (41\%) had cervical cancer. Among $134 \mathrm{HPV}$ negative women, only 4 (3\%) had cancer, $6(4.5 \%)$ had CIN1, and $2(1.5 \%)$ had CIN2-3. Overall, 31 distinct HPV genotypes were detected, and their detection rates, including co-infection with more than one genotype are illustrated in Table 2. The prevalence of HPV infection increased with lesion grade: $14 \%$ in controls, $67 \%$ in CIN1 cases, $88 \%$ in CIN2/3 and $89 \%$ in ICC.

\section{HPV genotypes in women with CIN1}

HPV DNA was detected in $67 \%$ of CIN1, and $50 \%$ of the HPV detected were of HR genotypes. On average, there were approximately $3 \mathrm{HPV}$ genotypes per CIN1 case (range 0-9). Sixty percent of women with CIN1 lesions had multiple infections. In order of prevalence, the seven most frequent HR-HPV genotypes detected among CIN1 cases were: 35, 45, 53, 58, 59, 16, and 51, followed by low risk (LR) type HPV55. In two individuals the rare HPV62 type was detected (Table 2).

\section{HPV genotypes in women with CIN2-3}

HPV DNA was detected in $88 \%$ of CIN2-3; on average 4 HPV genotypes were detected per case (range, 0-9) as also found for women with CIN1. High-risk HPV subtypes were found either as single or multiple infections in $57 \%$ of CIN2-3 cases. In contrast to $73 \%$ of ICC which harbored the HPV16 genotype, only 3 (14\%) CIN2-3 cases, 2 (17\%) CIN1 cases and four controls (15\%) had detectable HPV16 DNA. Multiple HPV infections were also common among CIN2-3 cases with 75\% showing HPV coinfections. Also as in CIN1, 50\% of the HPV genotypes detected were HR while the remainder were LR or other types of unknown oncogenic potential. HPV53, 58, 16, 18, 31, 33, and 35, were the seven most frequent types detected among women with CIN2-3, in order of decreasing frequency (Table 2). LR-HPV genotypes were detected in CIN1 and CIN2-3 lesions only in the context of multiple infections with $\mathrm{HR}$ genotypes.

\section{HPV genotypes in women with ICC}

HPV DNA was detected in $89 \%$ of ICC biopsies with an average of 3 genotypes per case (range 0-6). High-risk HPV subtypes were found either as single or multiple infections in $78 \%$ of ICC. Most ( 73\%) of the ICC cases harbored the HPV16 genotype either as a single infection $(15 \%)$ or along with other HR $(30 \%)$ or LR $(9.1 \%)$ genotypes. In contrast, HPV 16 was rare in women with lower CIN grades as only 2 of 14 (14\%) CIN2-3, 2 of 12 (17\%) CIN1, and 3 of 20 (15\%) of women with no evidence of cytological abnormalities harbored HPV16 infections. Following HPV16, the next most frequent genotypes in ICC were HPV35, 45, 18, 31, 52, 33 and 58 (Table 2). These frequencies were all statistically significantly higher than in controls. Interestingly, HPV18 was found in $21 \%$ of ICC, and only when HPV16 was also present.

\section{Single versus Multiple HPV Infections}

Table 3 shows the distribution of single and multiple HPV infections by lesion grade and cervical cancer 
Table 1 Socio-demographic characteristics of study participants

\begin{tabular}{|c|c|c|c|c|c|c|c|c|c|}
\hline & $\begin{array}{l}\text { Can } \\
\text { (n }=\end{array}$ & & $\begin{array}{l}\mathrm{CIN} \\
(\mathrm{n}=\end{array}$ & & $\begin{array}{c}\mathrm{Cl} \\
(\mathrm{n}=\end{array}$ & & $\begin{array}{l}\text { CONT } \\
(\mathrm{n}=\end{array}$ & & p-values** \\
\hline & $\mathrm{n}$ & $\%$ & $\mathbf{n}$ & $\%$ & $\mathrm{n}$ & $\%$ & $\mathrm{n}$ & $\%$ & \\
\hline Age & 55.2 & 12.3 & 44.7 & 9.8 & 35.7 & 12.2 & 40.3 & 9.9 & $<0.0001$ \\
\hline Income \$ & 18 & 28 & 39 & 53 & 65 & 80 & 78 & 95 & $<0.0001^{* * *}$ \\
\hline Lifetime sexual partner & & & & & & & & & $0.4^{*}(1,2,3,4)$ \\
\hline 1 & 24 & 52.2 & 7 & 43.8 & 5 & 25 & 62 & 56.5 & \\
\hline 2 & 19 & 41.3 & 6 & 37.5 & 11 & 55 & 56 & 39.2 & \\
\hline 3 & 3 & 6.5 & 2 & 12.5 & 4 & 20 & 20 & 14 & \\
\hline 4 & 0 & 0 & 1 & 6.3 & 0 & 0 & 2 & 1.4 & \\
\hline None & 2 & & 1 & & 1 & & 5 & & \\
\hline Marital status & & & & & & & & & $0.6^{*}$ \\
\hline Married & 30 & 62.5 & 10 & 58.8 & 15 & 71.4 & 107 & 72.3 & \\
\hline Non-married & 18 & 37.5 & 7 & 41.2 & 6 & 28.5 & 40 & 27 & \\
\hline HPV & & & & & & & & & $<0.0001$ \\
\hline Any & 33 & 89.2 & 14 & 87.5 & 12 & 66.7 & 20 & 14.1 & \\
\hline None & 4 & 10.8 & 2 & 12.5 & 6 & 33.3 & 122 & 85.9 & \\
\hline Genotypes per Case & 2.8 & & 3.7 & & 2.7 & & 2.1 & & \\
\hline Current Smoke & & & & & & & & & $0.6^{*}$ \\
\hline Yes & 2 & 4.2 & 0 & 0 & 0 & 0 & 3 & 2 & \\
\hline No & 46 & 95.8 & 17 & 100 & 21 & 100 & 144 & 98 & \\
\hline Oral contraception use & & & & & & & & & 0.003 \\
\hline Yes & 19 & 39.6 & 10 & 58.8 & 16 & 76.2 & 98 & 67.6 & \\
\hline No & 29 & 60.4 & 7 & 41.2 & 5 & 23.8 & 47 & 32.4 & \\
\hline HIV-1 infection & & & & & & & & & $<0.0001^{*}$ \\
\hline Yes & 6 & 19.4 & 9 & 81.8 & 9 & 64.3 & 23 & 20.9 & \\
\hline No & 25 & 50.6 & 2 & 18.2 & 5 & 35.7 & 87 & 79.1 & \\
\hline Tribe & & & & & & & & & 0.3 \\
\hline Chagga & 21 & 43.8 & 12 & 70.6 & 10 & 47.6 & 84 & 57.1 & \\
\hline Pare & 10 & 20.8 & 3 & 17.7 & 2 & 9.5 & 21 & 14.3 & \\
\hline Others & 17 & 35.4 & 2 & 11.8 & 9 & 42.9 & 42 & 28.6 & \\
\hline
\end{tabular}

- * p-values is from fisher's exact chi-squared test due to small cell

- ** p-values are exclude missing

.*** Poisson regression

- Numbers do not necessarily add up to the total due to missing values

status. HR-HPV 18, 35, 45 and 31, together with HPV16 were detected in $60.6 \%$ of ICC cases. HR-HPV genotypes 33, 52, 58, 68 and 82, in multiple infections with HPV 16, were detected in $30.3 \%$ of ICC cases. When combined, HR-HPV genotypes 16, 18, 31, 33, $35,45,52,58,68$, and 82 , they accounted for $90.9 \%$ of all HPV positive ICC cases. HPV16 multiple infections with LR-HPV genotypes 6, 11, 61, and 81 and other HPV genotypes (62 and 73), comprised the remaining 9.1\% of HPV positive ICC cases. Among all CIN cases, HPV16 was not the prevalent genotype detected; 93\% of CIN2-3 and all of CIN1 cases had multiple infections with HPV18, 26, 35, 45, 51, 53, 56, 58, 59, and 66 (Table 3). Whereas of 120 controls or women with no evidence of cytological or histological abnormalities, only 20 (14\%) were HPV-positive, in which $90 \%$ of multiple infections we detected harbored the same genotypes (HPV18, 26, 35, 45, 51, 53, 56, 58, 59, and 66 (Table 3).

\section{Discussion}

Our key finding was that among women visiting the $\mathrm{KCMC}$, a tertiary care facility serving 10 million people, in Northern Tanzania, HPV16, 35 and 45 alone accounted for most of the invasive cervical cancers found. These HPV genotypes were rare in CIN lesions regardless of grade, suggesting that a vaccine that includes these three genotypes could prevent $\sim 70 \%$ of ICC. Our findings also suggest that ICC risk is higher in individuals infected with multiple HPV genotypes, including those considered as high and low risk, suggesting that the cumulative burden of HPV multiple infections, maybe a marker of differential immune response. We did not detect any HPV DNA in $11 \%$ of 
Table 2 Distribution of HPV types in CIN1, CIN2, CIN3 and Cervical cancer

\begin{tabular}{|c|c|c|c|c|c|c|c|c|}
\hline \multirow[t]{2}{*}{ HPV test results } & \multicolumn{2}{|c|}{$\begin{array}{c}\text { Cancer } \\
(\mathrm{n}=33) \\
(\%)\end{array}$} & \multicolumn{2}{|c|}{$\begin{array}{c}\text { CIN2- } 3 \\
(n=14) \\
(\%)\end{array}$} & \multicolumn{2}{|c|}{$\begin{array}{c}\text { CIN1 } \\
(n=12) \\
(\%)\end{array}$} & \multicolumn{2}{|c|}{$\begin{array}{c}\text { Controls } \\
(n=20) \\
(\%)\end{array}$} \\
\hline & Single & Multiple & Single & Multiple & Single & Multiple & Single & Multiple \\
\hline High-risk HPV type & $\mathrm{n}=8$ & $\mathrm{n}=70$ & $\mathrm{n}=3$ & $\mathrm{n}=28$ & $\mathrm{n}=4$ & $\mathrm{n}=22$ & $\mathrm{n}=4$ & $n=29$ \\
\hline \multicolumn{9}{|l|}{ Group 1} \\
\hline 16 & 62.5 & 72.7 & 33.3 & 14.2 & 0 & 16.6 & 16.6 & 15.0 \\
\hline 18 & 0 & 21.2 & 33.3 & 14.2 & 0 & 0 & 16.6 & 10.0 \\
\hline 31 & 0 & 18.1 & 0 & 14.2 & 0 & 0 & 0 & 5.0 \\
\hline 33 & 0 & 9.09 & 0 & 14.2 & 0 & 0 & 0 & 0.0 \\
\hline 35 & 25.0 & 33.3 & 0 & 14.2 & 25.0 & 25.0 & 0 & 15.0 \\
\hline 39 & 0 & 0 & 0 & 0 & 0 & 8.3 & 0 & 0 \\
\hline 45 & 12.5 & 30.3 & 0 & 7.14 & 0 & 25.0 & 16.6 & 10.0 \\
\hline 51 & 0 & 0 & 33.3 & 14.2 & 25.0 & 16.6 & 0 & 10.0 \\
\hline 52 & 0 & 15.1 & 0 & 0 & 0 & 8.3 & 0 & 15.0 \\
\hline 56 & 0 & 0 & 0 & 7.14 & 0 & 0 & 0 & 5.0 \\
\hline 58 & 0 & 6.06 & 0 & 28.5 & 50.0 & 25.0 & 33.3 & 25.0 \\
\hline 59 & 0 & 0 & 0 & 7.14 & 0 & 25.0 & 0 & 5.0 \\
\hline Low-risk HPV type & $\mathrm{n}=0$ & $n=17$ & $\mathrm{n}=0$ & $n=8$ & $n=0$ & $n=7$ & $n=3$ & $n=10$ \\
\hline \multicolumn{9}{|l|}{ Group 2A } \\
\hline 68 & 0 & 3.03 & 0 & 7.14 & 0 & 0 & 0 & 5.0 \\
\hline \multicolumn{9}{|l|}{ Group 2B } \\
\hline 26 & 0 & 0 & 0 & 0 & 0 & 0 & 33.3 & 5.0 \\
\hline 53 & 0 & 0 & 0 & 35.7 & 0 & 25.0 & 0 & 5.0 \\
\hline 66 & 0 & 0 & 1 & 14.2 & 0 & 0 & 33.3 & 15.0 \\
\hline 70 & 0 & 0 & 0 & 0 & 0 & 8.3 & 0 & 10.0 \\
\hline 73 & 0 & 15.1 & 0 & 21.4 & 0 & 8.3 & 0 & 15.0 \\
\hline 82 & 0 & 3.03 & 0 & 7.14 & 0 & 8.3 & 33.3 & 10.0 \\
\hline \multicolumn{9}{|l|}{ Group 3} \\
\hline 6 & 0 & 33.3 & 0 & 7.14 & 0 & 0 & 0 & 0 \\
\hline 11 & 0 & 9.09 & 0 & 0 & 0 & 8.3 & 0 & 0 \\
\hline Other types & $n=0$ & $n=6$ & $\mathrm{n}=1$ & $n=16$ & $\mathrm{n}=0$ & $\mathrm{n}=4$ & $\mathrm{n}=1$ & $n=3$ \\
\hline 40 & 0 & 0 & 0 & 0 & 0 & 0 & 0 & 0 \\
\hline 42 & 0 & 0 & 0 & 7.14 & 0 & 8.3 & 100 & 5.0 \\
\hline 55 & 0 & 3.03 & 0 & 7.14 & 0 & 16.6 & 0 & 5.0 \\
\hline 61 & 0 & 0 & 0 & 7.14 & 0 & 8.3 & 0 & 5.0 \\
\hline 62 & 0 & 3.03 & 0 & 21.4 & 0 & 16.6 & 0 & 0 \\
\hline 69 & 0 & 0 & 0 & 14.2 & 0 & 0 & 0 & 0 \\
\hline 72 & 0 & 0 & 0 & 7.4 & 0 & 8.3 & 0 & 5.0 \\
\hline 81 & 0 & 6.06 & 0 & 21.4 & 0 & 0 & 0 & 10.0 \\
\hline 83 & 0 & 0 & 0 & 28.5 & 0 & 16.6 & 0 & 0 \\
\hline 84 & 0 & 0 & 100 & 28.5 & 0 & 0 & 0 & 0 \\
\hline
\end{tabular}

ICC cases, a proportion within the $6-16 \%$ range of HPVnegativity in ICC previously found [11], and similar to the $11.5 \%$ reported elsewhere [8].

While findings of HPV16 association with ICC are consistent with -current knowledge, our data also suggest that in addition, HPV35 and HPV45 may increase risk, as observed in a global meta-analysis study [23]. This interpretation is consistent with data found in other African countries, where HPV16 and HPV18 were less common than other HR types in CIN1, though involved in more advanced lesions and cervical cancer [24-28]. Most of these studies used fresh biopsies for HPV detection [24,26,27]. We detected HR-HPV16 in $73 \%$ of ICC cases, including single and multiple infections. In the US, HPV16 and 18 combined are found in cervical cancer at a rate of $70.2 \%$ [23], similar to findings in a Canadian study: HPV16 DNA in $52.1 \%$ of ICC and HPV18 DNA in $18.1 \%$ of ICC [8]. However, the 
Table 3 Distribution of HPV16 and other most prevalent genotypes in CIN lesions and ICC

\begin{tabular}{lcccc}
\hline \multicolumn{1}{c}{ HPV genotypes } & $\begin{array}{c}\text { ICC } \\
\text { Total (\%) } \\
\mathbf{n}=\mathbf{3 3}\end{array}$ & $\begin{array}{c}\text { CIN2-3 } \\
\text { Total (\%) } \\
\mathbf{n}=\mathbf{1 4}\end{array}$ & $\begin{array}{c}\text { CIN-1 } \\
\text { Total (\%) } \\
\mathbf{n}=\mathbf{1 2}\end{array}$ & $\begin{array}{c}\text { Controls } \\
\text { Total (\%) } \\
\mathbf{n}=\mathbf{2 0}\end{array}$ \\
\hline HPV-16 only & $5(15.1)$ & $1(7.1)$ & $0(0.0)$ & $1(5.0)$ \\
HPV16 with HPV-18 only & $5(15.1)$ & $2(14.2)$ & $0(0.0)$ & $2(10.0)$ \\
HPV16 with HPV 18,35,45, or 31 & $20(60.6)$ & $2(14.2)$ & $1(8.3)$ & $3(15.0)$ \\
HPV16 with HPV 18,31,33,35,45,52,58,68,82 & $30(90.9)$ & $2(14.2)$ & $1(8.3)$ & $3(15.0)$ \\
HPV16 with HPV 6, 11,18,31,33,35,45,52,58,61,62,68,73,81,82 & $33(100)$ & $3(21.3)$ & $2(16.6)$ & $4(20.0)$ \\
Other HR-HPV single infections 18,35,45,51,58,66 & $33(100)$ & $4(28.6)$ & $6(50.0)$ & $8(40.0)$ \\
HPV 18,26,35,45,51,53,56,58,59,66, excluding HPV16 & $33(100)$ & $13(92.8)$ & $12(100)$ & $18(90.0)$ \\
HPV 18,26,35,42,45,51,53,55,56,58,59,61,66,69,70,72,81,83,84, excluding HPV16 & $33(100)$ & $14(100)$ & $12(100)$ & $20(100)$ \\
\hline
\end{tabular}

percentage of African women in the Canadian study was $3.9 \%$ and geographic regions of origin are unknown, while our population was $100 \%$ African $[8,29]$. If these results can be replicated in a larger study, our findings would suggest that the association of HPV16 and ICC in the Tanzanian region may be much higher than that in other populations. Also, we found five ICC cases with HPV16 single-genotype infection. However, there were no ICC cases with single-genotype HPV18 infection.

HPV 35/45/6 and 18/31/73 were the next most frequent genotypes detected in ICC, partly matching reports by others, where HPV31, 33 and 45 were among the six most frequently detected genotypes in ICC in North America [8-10,23]. Our results are similar to those of the Canadian study, where HPV45 was one of the three most prominent genotypes in ICC, ranking ahead of HPV31 and 33 [8]. We could not identify a clear trend for a specific HPV type that would suggest lesion progression into cervical cancer. However, HPV 35 and 58 were the only types detected in CIN1, CIN2-3 and ICC. HR-HPV genotypes 16, 35 and 45 were the major genotypes found in cervical cancer cases.

Our results show some interesting differences with global cervical cancer data. The most frequent genotypes we detected in CIN1 were HPV35, 45 and 53/58/59, which differ from the most common types detected in CIN1 in the US, including HPV16, 66, 31, 52 and 51 [10], and HPV 16, 51, 52, 39, 18, 31 in Canada [8]. In CIN2-3 lesions, we predominantly detected HR-HPV 53 and 58 , and the rare genotypes HPV83 and 84 . These findings contrast with those suggesting that the most prevalent genotypes found in CIN2-3 in the US were HPV16, 31 and 18, however HPV58 ranked most frequently after 16,31 , and 18 [9,10,23,30]. Disparities among these studies may be due in part to different methodologies employed; however the evidence suggests that geographical differences contribute to HPV type distribution in cervical intraepithelial neoplasias across global regions, as reported [23].
The finding that HPV58 was the most prevalent genotype, followed by $16,35,52,66$, and 73 in equal proportions, are partly consistent with those of a recent metaanalysis in which the most common HPV genotypes among women with normal cytology in Eastern Africa are HPV52, 16, 18, 53 and 66, in order of prevalence [31]. In a study in Northwestern Tanzania [17] HPV16 and 33 were the main genotypes present in women with HSIL or advanced CIN; however this study had a small HSIL sample size (5 of 19 women) and no cancer cases. The most common genotypes detected among LSIL and HSIL cases were HPV16, 58, 33 and 18. In Mozambique, HPV35 was detected as the most prevalent type among HPV-positive women and among women with HSIL [14]. A Zimbabwean study found HPV16, 58, 18 and 52 to be the most common genotypes [32] in HIV-1 seropositive women with multiple HPV infections. But a European population-based study could not verify the oncogenic potential for HPV 58 and 59 in Icelandic women [7]. In our study, our rankings were not influenced by HIV-1 infection, (data not shown).

Findings that multiple HPV infections were more common than single infections in CIN1, CIN2-3 and cancer cases match reports by others [8,33-35]. While it has been shown that the risk for persistent infection with one HPV genotype is not synergistically enhanced by an existing infection with another genotype $[11,36,37]$, others [38] suggest local levels of HPV-specific immunoglobulin G (IgG) and IgA in the infected tissue may be insufficient to clear viral infections [38]. Thus, factors that affect humoral immunity, such as genetic predisposition, frequency of re-infection, genetic variations of the HPV genotype, and hormone levels could explain, at least in part, the association between multiple HPV infections and CIN and ICC in this region. When adjusting for HIV-1 infections in HPVpositive women, we found $50 \%$ more CIN1 and CIN2-3 lesions in HIV-1 seropositive women with HPV multiple infections (65\%), than in HIV-1 seronegative ones (30\%). While this would support the hypothesis that 
immunocompromised individuals are at higher risk of acquiring multiple infections, $84 \%$ of the ICC cases here reported were HIV-1 negative individuals, (data not shown).

The main limitation of our study is that these analyses relied on a small number of cases. However, findings contribute to HPV knowledge in East Africa that will be useful for vaccine development and to augment screening strategies. East Africa continues to have one of the highest ICC incidence and mortality [39], and cytologybased screening coverage remains low. Another limitation is that HPV DNA was detected from exfoliated cells for CIN cases and controls as biopsies were not medically indicated. Thus, some of the HPVs detected may not have been related to lesions subsequently detected. However, cells from homogenized biopsy specimens were used for HPV detection in the all squamous cell ICC cases. Therefore, limitations notwithstanding, our ICC findings support the hypothesis that the cumulative burden of multiple HPV genotypes may contribute to ICC incidence, presumably via altered immune response.

\section{Conclusions}

We found that HPV 16, 35 and 45, but not HPV18, were the most common HPV subtypes in ICC. HR-HPV genotypes 45,53 and 58 significantly contribute to CIN1, CIN2-3 and ICC rates in Northern Tanzanian women. Multiple infections were found in the majority of cancers and high grade CIN. Our data suggest that a vaccine targeting HPV genotypes 16, 18, 31, 35 and 45, could help prevent up to $61 \%$ of ICC in this region; while adding HPV genotypes $33,52,58,68$, and 82 may help increase prevention up to $91 \%$ of ICC. The low frequency or absence of HPV 16 and 18 in CIN1 or CIN23 may have implications for promoting cytology and HPV-based screening in this region. Larger studies are required to confirm these findings.

\section{Acknowledgements}

This paper was supported in part by grants from the National Institutes of Health K01 CA104517, R01CA142983, R01CA142983-02S1 and Duke CFAR grant number 5P30 Al 064518 .

\footnotetext{
Author details

'Department of Community and Family Medicine, and Program of Cancer Detection, Prevention and Control, Duke University School of Medicine, Durham, NC, USA. ²Department of Obstetrics and Gynecology, Division of Gynecologic Oncology, Duke University School of Medicine, Durham, NC, USA. ${ }^{3}$ University of Hawaii Cancer Center, Honolulu, HI, USA. ${ }^{4}$ Department of Obstetrics and Gynecology, Duke University School of Medicine, Durham, NC, USA. ${ }^{5}$ Division of Infectious Diseases, Department of Medicine and Duke Global Health Institute, Duke University School of Medicine, Durham, NC, USA. ${ }^{6}$ Department of Obstetrics and Gynecology, Kilimanjaro Christian Medical Centre, Tumaini University, Moshi, Tanzania. ${ }^{7}$ Department of Epidemiology, University of North Carolina, Chapel Hill, NC, USA. ${ }^{8}$ Department of Medical Microbiology, Radboud University Nijmegen Medical Centre, Nijmegen, The Netherlands.
}

\section{Authors' contributions}

AV analyzed the data, run the statistical analysis and drafted the manuscript. SKM participated in the design of the study and in the drafting of the manuscript. BYH carried out the HPV genotyping. BV participated in the study design and coordination. JAB, OO, PM and JO actively participated in the overseeing of the recruitment, sample collection, and study design. FO managed the data. JSM and MVDK participated in the drafting of the manuscript. $\mathrm{CH}$ conceived of the study, participated in its design, coordination, and data analysis and participated in drafting the manuscript. All authors read and approved the final manuscript.

\section{Competing interests}

The authors declare that they have no competing interests.

Received: 9 September 2011 Accepted: 14 November 2011 Published: 14 November 2011

\section{References}

1. Ferlay J, Shin HR, Bray F, Forman D, Mathers C, Parkin DM: Estimates of worldwide burden of cancer in 2008: GLOBOCAN 2008. Int J Cancer 2008, 127:2893-2917.

2. Bosch FX, Lorincz A, Munoz N, Meijer CJL, Shah KV: The causal relationship between human papillomavirus and cervical cancer. J Clin Pathol 2002, 55:244-265.

3. Jung WW, Chun T, Sul D, Hwang KW, Kang HS, Lee DJ, Han IK: Strategies Against Human Papillomavirus Infection and Cervical Cancer. J Microbiol 2004, 42:255-266.

4. Tjalma WAA, Arbyn M, Paavonen J, Van Waes TR, Bogers JJ: Prophylactic human papillomavirus vaccines: the beginning of the end of cervical cancer. Int J Gynecol Cancer 2004, 14:751-761.

5. Baseman JG, Koutsky LA: The epidemiology of human papillomavirus infections. Review. J Clin Virol 2005, 32(Suppl):S16-S24.

6. JM M, Jacobs MV, Manos MM, Bosch FX, Kummer JA, Shah KV, Snidjers PJ, Peto J, Meijer CJL, Munoz N: Human papilomavirus is a necessary cause of invasive cervical cancer worldwide. J Pathol 1999, 189:12-19.

7. Sigurdsson K, Taddeo FJ, Benediktsdottir KR, Olafsdottir K, Sigvaldason H, Oddsson K, Rafnar T: HPV genotypes in CIN 2-3 lesions and cervical cancer: a population-based study. Int J Cancer 2007, 121:2682-2687.

8. Coutlee F, Ratnam S, Ramanakumar AV, Insinga RP, Bentley J, Escott N, Ghatage P, Koushik A, Ferenczy A, Franco EL: Distribution of human papillomavirus genotypes in cervical intraepithelial neoplasia and invasive cervical cancer in Canada. J Med Virol 2011, 83:1034-1041.

9. Clifford GM, Smith JS, Aguado T, Franceschi S: Comparison of HPV type distribution in high-grade cervical lesions and cervical intraepithelial neoplasia grade 3. Cancer Epidemiol Biomarkers Prev 2003, 19:1675-1681.

10. Insinga RP, Liaw KL, Johnson LG, Madeleine MM: A systematic review of the prevalence and attribution of human papillomavirus types among cervical, vaginal, and vulvar precancers and cancers in the Unites States. Cancer Epidemiol Biomarkers Prev 2008, 17:1611-11622.

11. Munoz N, Bosch FX, Castellsague X, Diaz M, de-SanJose S, Hammouda D, Shah KV, Meijer CJL: Against which human papillomavirus types shall we vaccinate and screen? The international perspective. Int J Cancer 2004, 111:278-285.

12. Clifford GM, Smith JS, Plummer M, Munoz N, Franceschi S: Human papillomavirus types in invasive cervical cancer worldwide: a metaanalysis. Br J Cancer 2003, 88:63-73.

13. Cuzick J, Arbyn M, Sankaranarayanan R, Tsu V, Ronco G, Mayrand MH, Dillner J, Meijer CJLM: Overview of human papillomavirus-based and other novel options for cervical cancer screening in developed and developing countries. Vaccine 2008, 265:K29-K41.

14. Castellsague $X$, Menendez C, Loscertales MP, Kornegay JR, dos Santos F, Gomez-Olive FX, Lloveras B, Abarca N, Vaz N, Barreto A, Bosch FX, Alonso P: Human papillomavirus genotypes in rural Mozambique. Lancet 2001, 358:1429-1430.

15. De Vuyst $H$, Steyaert $S$, Van Renterghem L, Claeys P, Muchiri L, Sitati S, Vansteelandt S, Quint W, Kleter B, Van Marck E, Temmerman M: Distribution of human papillomavirus in a family planning population in Nairobi, Kenya. Sex Transm Dis 2003, 30:137-142.

16. Wall SR, Scherf CF, Morrison L, Hart KW, West B, Ekpo G, Fiander AN, Man S, Gelder CM, G. Walraven G, Borysiewicz LK: Cervical human papilloma virus infection and squamous intraepithelial lesions in rural Gambia, West- 
Africa: viral sequence analysis and epidemiology. $\mathrm{Br} J$ Cancer 2005, 93:1068-1076

17. Mayaud P, Weiss HA, Lacey CJN, Gill DK, Mabey DCW: Genital human papillomavirus genotypes in Northwestern Tanzania. J Clin Microbiol 2003, 41:4451-4453.

18. Didelot-Rousseau MN, Nagot N, Costes-Martineau V, Valles X, Ouedraogo A, Konate I, Weiss HA, Van de Perre P, Mayaud P, Segondy M: Human papillomavirus genotype distribution and cervical squamous intraepithelial lesions among high-risk women with and without HIV-I infection in Burkina Faso. Br J Cancer 2006, 95:355-362.

19. Apgar BS, Zoschnick L, Wright TC: The 2001 Bethesda system terminology. Am Fam Physician 1998, 68:10.

20. Gravitt PE, Kamath AM, Gaffikin L, Chirenje ZM, Womack S, Shah KV: Human papillomavirus genotype prevalence in high-grade squamous intraepithelial lesions and colposcopically normal women from Zimbabwe. Int J Cancer 2002, 100:729-732.

21. Mayhood MK, Afwamba IA, Odhiambo CO, Ndanu E, Thielman NM, Morrissey AB, Shao JF, Wells Pence B, Crump JA: Validation, performance under field conditions, and cost-effectiveness of Capiullus HIV-1/HIV-2 and Determine HIV1/2 rapid human immunodeficiency virus antibody assays using sequencial and parallel testing algorithms in Tanzania. $J$ Clin Microbiol 2008, 46:3946-3951.

22. Bouvard V, Baan R, Straif K, Grosse Y, Secretan B, El Ghissassi F, BenbrahimTallaa L, Guha N, Freeman C, Galichet L, Cogliano V: WHO International agency for research on cancer monograph working group: a review of human carcinogenesis - Part B: biological agents. Lancet Oncol 2009, 10:321-322.

23. Smith JS, Lindsay L, Hoots B, Keys J, Franceschi S, Winer R, Clifford GM: Human papillomavirus type distribution in invasive cervical cancer and high-grade cervical lesions: a meta-analysis update. Int J Cancer 2007, 121:621-632.

24. Ter Meulen J, Eberhardt HC, Luande J, Mgaya HN, Chang-Claude J, Mtiro H, Minha M, Kashaija P, Yu X, Meinhardt G, Gissman L, Pawlita M: Human papillomavirus (HPV) infection, HIV-1 infection and cervical cancer in Tanzania, East Africa. Int J Cancer 1992, 51:515-521.

25. Chabaud M, Le Cann P, Mayelo V, Leboulleux D, Diallo AS, Enogat N, Afoutou JM, Anthonioz P, Coll-Seck AM, Coursaget P: Detection by PCR of human papillomavirus genotypes in cervical lesions of Senegalese women. J Med Virol 1996, 49:259-263.

26. La Ruche G, You B, Mensah-Ado I, Bergeron C, Montcho C, Ramon R, ToureCoulibaly K, Welffens-Ekre C, Dabis F, Orth G: Human papillomavirus and human immunodeficiency virus infections: relation with cervical dysplasia - neoplasia in African women. Int J Cancer 1998, 76:480-486.

27. Bayo S, Bosch FX, de Sanjose S, Munoz N, Combita AL, Coursaget P, Diaz M, Dolo A, van den Brule AJ, Meijer CLL: Risk factors of invasive cervical cancer in Mali. Int J Epidemiol 2002, 31:202-209.

28. Kay P, Soeters R, Nevin J, Denny L, Dehaeck CMC, Williamson AL: High prevalence of HPV16 in South African women with cancer of the cervix and cervical intraepithelial neoplasia. J Med Virol 2003, 71:265-273.

29. Koushik A, Ghosh A, Duarte-Franco E, Forest P, Voyer H, Matlashewski G, Coutlee F, Franco EL: The p53 codon 72 polymorphism and risk of highgrade cervical intraepithelial neoplasia. Cancer Detect Prev 2005, 29:307-316.

30. Castle PE, Schiffman M, Wheeler CM, Wentzensen N, Gravitt PE: Human papillomavirus genotypes in cervical intraepithelial neoplasia grade 3 . Cancer Epidemiol Biomarkers Prev 2010, 19:1675-1681.

31. de San Jose S, Diaz M, Castellsague X, Clifford G, Bruni L, Munoz N, Bosch FX: Worldwide prevalence and genotype distribution of cervical human papillomavirus DNA in women with normal cytology: a metaanalysis. Lancet Infect Dis 2007, 7:453-459.

32. Gravitt PE, Kamath AM, Gaffikin L, Chirenje ZM, Womack S, Shah KV: Human papillomavirus genotype prevalence in high-grade squamous intraepithelial lesions and colposcopically normal women from Zimbabwe. Int J Cancer 2002, 100:729-732.

33. Adam E, Kaufman RH, Berkova Z, Icenogle J, Reeves WC: Is human papillomavirus testing an effective triage method for detection of highgrade (grade 2 or 3) cervical intraepithelial neoplasia? Am J Obstet Gynecol 1998, 178:1235-1244.

34. Ho GYF, Kadish AS, Burk RD, Basu J, Palan PR, Mikhail M, Romney SL: HPV 16 and cigarette smoking as risk factors for high-grade cervical intraepithelial neoplasia. Int J Cancer 1998, 78:281-285.
35. McLehose RF, Harpster A, Lanier AP, Schiff MA, Koehler K, Murphy N, Becker TM: Risk factors for cervical intraepithelial neoplasm in Alaska Native women: a pilot study. Alaska Med 1999, 41:76-85.

36. Liaw KL, Hidelsheim A, Burk RD, Gravitt P, Wacholder S, Manos MM, Scott DR, Scherman ME, Kurman RJ, Glass AG, Anderson SM, Schiffman MA: A prospective study of human papillomavirus (HPV) type 16 DNA detection by polymerase chain reaction and its association with acquisition and persistence of other HPV types. J Infect Dis 2001, 183:8-15.

37. Bosch XF, de Sanjose S: Human papillomavirus and cervical cancerburden and assessment of causality. I Nat/ Cancer Inst Monogr 2003, 31:3-13.

38. Bontkes $H J$, deGruijl TD, Walboomers JM, Schiller JT, Dillner J, Helmerhorst TJ, Vereheijen RH, Schper RJ, Meijer CJL: Immune responses against human papillomavirus (HPV) type 16 virus-like particles in a cohort study of women with cervical intraepithelial neoplasia. II. Systemic but not local IgA responses correlate with clearance of HPV-16. J Gen Virol 1999, 80:409-417.

39. Louie KS, de Sanjose S, Mayaud P: Epidemiology and prevention of human papillomavirus and cervical cancer in sub-Saharan Africa: a comprehensive review. Tropical Medicine and International Health 2009, 14:1287-1302.

doi:10.1186/1750-9378-6-20

Cite this article as: Vidal et al:: Distribution of HPV genotypes in cervical intraepithelial lesions and cervical cancer in Tanzanian women. Infectious Agents and Cancer 2011 6:20.

\section{Submit your next manuscript to BioMed Central and take full advantage of:}

- Convenient online submission

- Thorough peer review

- No space constraints or color figure charges

- Immediate publication on acceptance

- Inclusion in PubMed, CAS, Scopus and Google Scholar

- Research which is freely available for redistribution

Submit your manuscript at www.biomedcentral.com/submit
Ciomed Central 